\title{
Annealing of Te-implanted GaAs by ruby laser irradiation
}

\section{Citation}

Golovchenko, J. A., and T. N. C. Venkatesan. 1978. Annealing of Te-Implanted GaAs by Ruby Laser Irradiation. Applied Physics Letters 32, no. 3: 147. doi:10.1063/1.89962.

\section{Published Version}

doi:10.1063/1.89962

\section{Permanent link}

http://nrs.harvard.edu/urn-3:HUL.InstRepos:29407065

\section{Terms of Use}

This article was downloaded from Harvard University's DASH repository, and is made available under the terms and conditions applicable to Other Posted Material, as set forth at http:// nrs.harvard.edu/urn-3:HUL.InstRepos:dash.current.terms-of-use\#LAA

\section{Share Your Story}

The Harvard community has made this article openly available.

Please share how this access benefits you. Submit a story.

Accessibility 
${ }^{8}$ W. V. Mclevige, P.K. Chatterjee, and B.G. Streetman, J. Phys. E 10, 335 (1977).

${ }^{9}$ W. R. Runyan, Semiconductor Measurements and Instrumentation (McGraw-Hill, New York, 1975), p. 199.

${ }^{10} \mathrm{~K} . \mathrm{B}$. Wolfstim, Phys. Chem. Solids 16, 279 (1960).

${ }^{11}$ N. N. Gerasimenko, A.V. Dvurechenskii, S.I. Romanov, and L.S. Smirnov, Sov. Phys.-Semicond. 7, 1461 (1974).

${ }^{12}$ T. W. Sigmon (private communication).

${ }^{13}$ J.C.C. Tsai and J.M. Morabito, in Ref. 3, p. 115.

${ }^{14}$ L. Csepregi, J.W. Mayer, and T.W. Sigmon, Phys. Lett.
A 54, 157 (1975).

${ }^{15}$ B. L. Crowder, J. Electrochem. Soc. 118, 943 (1971).

${ }^{16} \mathrm{~J}$. F. Gibbons, Proc. IEEE 60, 1062 (1972).

${ }^{17}$ F. F. Morehead, Jr. and B. L. Crowder, Radiat. Eff. 6, 27 (1970).

${ }^{18}$ H.B. Dietrich, W.H. Weisenberger, and J. Comas, Appl. Phys. Lett. 28, 182 (1976).

${ }^{19}$ L. Csepregi, E. F. Kennedy, S. S. Lau, J.W. Mayer, and

T.W. Sigmon, Appl. Phys. Lett. 29, 645 (1976).

\title{
Annealing of Te-implanted GaAs by ruby laser irradiation
}

\author{
J. A. Golovchenko \\ Bell Laboratories, Murray Hill, New Jersey 07974
}

\section{T. N. C. Venkatesan}

Bell Laboratories, Crawford Hill Laboratories, Holmdel, New Jersey 07733

(Received 19 September 1977; accepted for publication 22 November 1977)

\begin{abstract}
A single pulse of ruby laser radiation is shown to cause significant regrowth in the amorphous region of heavily ion-implanted GaAs. The implanted $\mathrm{Te}$ atoms and the host material both show good channeling dips, suggesting essentially complete substitutionality of the Te. There has been only a minor redistribution of the tellurium atoms. The resulting local Te concentration in the laser-irradiated sample is more than ten times the known maximum solubility of $\mathrm{Te}$ in GaAs.
\end{abstract}

PACS numbers: 81.40.Ef, 61.70. $-\mathrm{r}, 79.20 . \mathrm{Ds}$

It is by now well known that not all of the initially anticipated advantages of doping semiconductors by ion implantation have been realized. Nevertheless the technique has been applied for practical applications to introduce controllable, homogeneous, and pure dopants near the surface of the host material from which it is subsequently diffused at high temperatures. The main problem with the ion-implantation technique lies in the massive crystal damage the ions introduce into the host material as they dissipate their initial kinetic energy in coming to rest. A major part of this energy is generally delivered to recoiling crystal atoms. The defects resulting from the subsequent large number of displaced atoms are usually extended and complex. For room -temperature implants of $\geq 10^{14}$ heavy ions $/ \mathrm{cm}^{2}$ most semiconductors are essentially devoid of any long-range order in the region where the implanted ions have come to rest. The electrical activity of such material is unsuitable for most applications. However, the material may then be heated to diffuse the impurity from this region and or anneal out the damage. Temperatures required for this step may be of the order of $900^{\circ} \mathrm{C}$. The details of the processing depend on doping levels, host material, and energy of implant.

A particularly complex case is that of implantation into gallium arsenide. The basic problem with this material is its decomposition above $\sim 200-300^{\circ} \mathrm{C}^{1}{ }^{1}$ Various solutions to the processing problems of GaAs, such as hot implantation ${ }^{2}$ and "capped" annealing to $900{ }^{\circ} \mathrm{C}$ with $\mathrm{SiO}_{2}$ or $\mathrm{Si}_{3} \mathrm{~N}_{4}$ layers, have been studied. ${ }^{3}$ We have picked GaAs as a test case for studying laser annealing because several of the possible advantages of the method seem well suited to this system.
Laser annealing of ion-implanted silicon has recently been reported by several groups in the Soviet Union, ${ }^{4}$ and confirmed by Italian workers. ${ }^{5}$ While not completely consistent nor understood, these results have provided guidance and stimulation in our initial experiments. Similar work on capped GaAs implanted with Te has been reported by Kachurin et $a l .{ }^{6}$ Laser annealing of uncapped GaAs seems not to have been investigated so far, and in view of the simplification the technique might allow in processing semiconductors, we chose to investigate this system.

Laser annealing consists simply of irradiating an ion-implanted sample with a single short pulse of intense laser radiation. The present experiment was per formed with a passively (i。e, dye) $Q$-switched ruby laser which delivered a 12-ns (FWHM) pulse of radiation in a roughly $1-\mathrm{cm}$-diam spot at $6943 \AA$. The maximum energy per pulse we have been able to extract from this particular laser (KORAD KQSIF) is $\sim 1.5 \mathrm{~J}$. Because of strain in the ruby crystal and multimode operation in the laser cavity, the spatial homogeneity of the laser pulse was quite poor. It was therefore passed through a ground glass plate and collimator which considerably homogenized the energy distribution across the beam at the expense of usable output.

A $\langle 100\rangle n$-type sample of GaAs was implanted at room temperature with $\sim 7 \times 10^{15} \mathrm{Te} / \mathrm{cm}^{2}$ at $50 \mathrm{keV}$. The projected range is roughly $100 \AA$ with straggle of $\sim 100 \AA$. The sample was then exposed to a pulse of $0.11 \mathrm{~J}$ over a 7-mm-diam spot. After implantation the samples had developed a "milky" appearance, characteristic of an amorphous layer in the implanted region. After the 
LASER AMMEAL OF GaAs (TE)

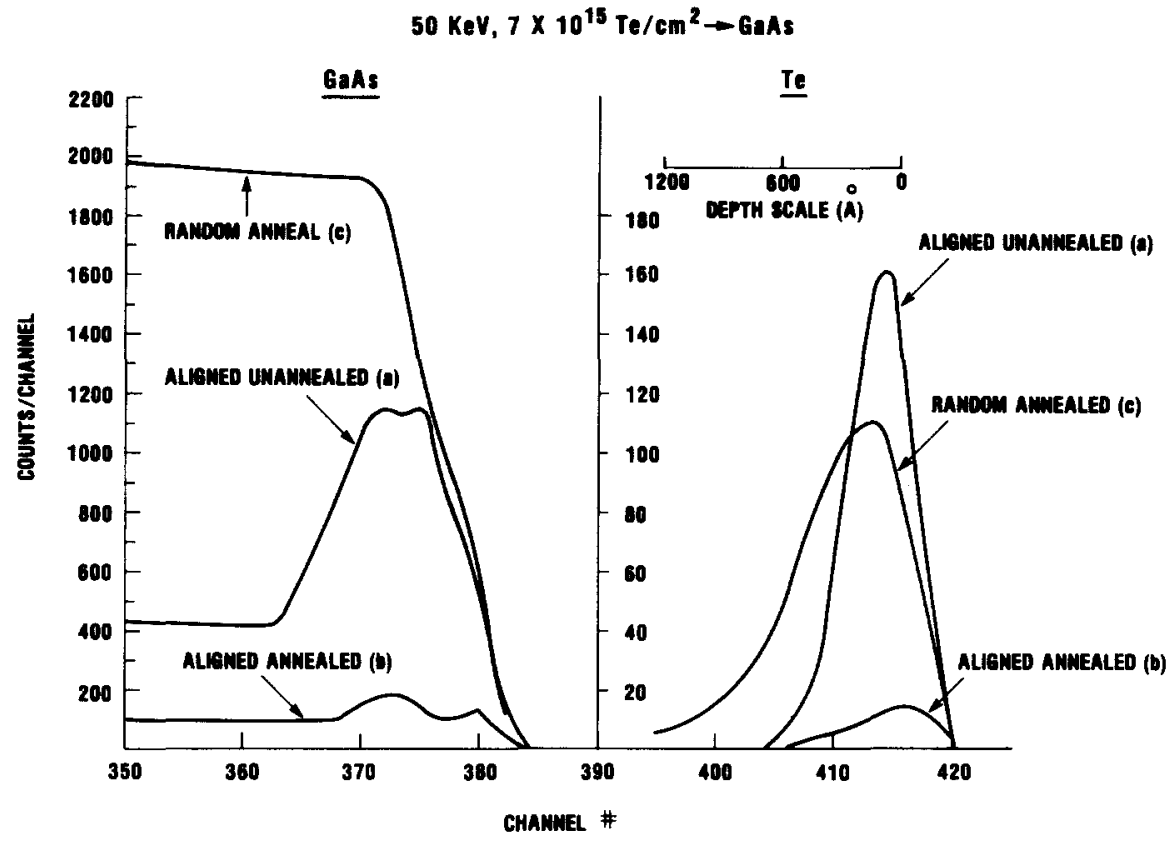

FIG. 1. Backscattering spectrum of $1.8-\mathrm{MeV} \alpha$ particles from $\langle 100\rangle$ GaAs (Te). One channel of the horizontal axis is $3.83 \mathrm{keV}$.

laser irradiation this appearance had disappeared and the characteristic metallic luster of the GaAs surface returned.

The sample was then studied using the Rutherford backscattering technique coupled with channeling ${ }^{7}$ to determine regrowth of the crystal and the substitutionality of the $\mathrm{Te}$. The results are shown in Fig. 1 which is an energy spectrum of incident $1.8-\mathrm{MeV} \alpha$ particles backscattered into a silicon surface barrier detector. Each channel on the horizontal axis corresponds to $3.83 \mathrm{keV}$ which converted to depth of penetration is roughly $60 \AA$. The detector resolution is four to five channels on this scale. The curves marked (a) show the aligned backscattering yield along the $\langle 100\rangle$ direction. Note the large damage peak near the surface (chan 365-385) corresponding to amorphous GaAs. Curve (b) shows the aligned backscattered energy spectrum after annealing. After the laser irradiation a minimum yield of $\sim 10 \%$ is obtained in the GaAs and a similar value was obtained for the $\mathrm{Te}$, indicating substantial regrowth of the host material with $\mathrm{Te}$ incorporated substitutionally. The nonaligned annealed spectrum is contained in curve (c). Comparison of the areas under the Te peak in curves (a) and (c) show no loss of Te during the anneal and suggest a slight in diffusion of a few hundred angstroms.

It seems quite remarkable to us that such a high substitutionality has been obtained in view of the extra ordinary high local concentration of $\mathrm{Te}\left(\sim 10^{21} / \mathrm{cm}^{3}\right)$ in the implanted layer which exceeds the solubility limit of Te in GaAs by more than an order of magnitude. ${ }^{8}$

In view of the above encouraging results from the ion scattering experiments, a similar implantation and laser anneal was carried out on a $p$-type zinc-doped $0.044 \Omega-\mathrm{cm}$ substrate. Four-point probe measurements on the electrically isolated Te-implanted region indicated a sheet resistivity of $\sim 300 \Omega / \square$, which corresponds to a resistivity of $\sim 10^{-3} \Omega \mathrm{cm}$. The diode formed had a reverse breakdown voltage of $\sim 4.5 \mathrm{~V}$. In spite of the large local concentration and substitutionality of $\mathrm{Te}$, the measured resistivity corresponds roughly to that obtained from conventional doping at the solubility limit. Thus either only a few percent of the Te atoms are contributing carriers or the mobility of the material has been degraded or some of both of the above has occurred. We expect that for lower dose implant this may be remedied.

It is anticipated that since the sample is laser annealing for only a short time (approximately $10^{-8} \mathrm{~s}$ ), significant decomposition of the GaAs does not occur. We believe that laser annealing could offer new opportunities to solve old problems in the fabrication of ionimplanted semiconductor devices, although it is clear that further studies particularly concentrating on residual defects in the annealed material are necessary.

We would particularly like to acknowledge Walter $M$. Gibson for introducing us to this field by making us aware of the Russian work cited in the references. In addition $\mathrm{J}$. Rodgers, R. Levesque, W. Augustyniak, and D. Huppert provided valuable technical aid. Jim North was helpful in making electrical measurements on our GaAs diodes. We are further thankful to $J_{0} . M$. Poate and S. L. McCall for lively discussions and to W. L. Brown and D. Gloge for encouragement. We are grateful to V.G. Keramidas for the GaAs samples.

${ }^{1} \mathrm{~S} . \mathrm{T}$. Picraux, in Ion Implantation in Semiconductors and Other Materials, edited by B.L. Crowder (Plenum, New York, 1973), p. 641.

${ }^{2}$ F.H. Eisen, J.S. Harris, B. Welch, J.D. Haskell, R.D. Pashley, and J.W. Mayer, in Ref. 1, p. 631 . 
${ }^{3}$ F. H. Eisen, B. M. Welch, H. Muller, K. Gamo, T. Inda, and J.W. Mayer, Solid-State Electron. 20, 219-223 (1977); A. Lidow, J.F. Gibbons, Appl. Phys. Lett. 31, 158 (1977). ${ }^{4}$ E.I. Shtyrkov, I. B. Khaibullin, M. M. Zaripov, M. F, Galyatudinov, and R.M. Bayazitov, Sov. Phys.-Semicond. 9, 1309 (1 976); A. Kh. Antonenko, N. N. Gerasimenko, A.V. Dvurechenskii, L.S. Smirnov, and G. M. Tseitlin, Sov. Phys. -Semicond. 10, 265 (1976); O. G. Kutukov and L. N. Strel'tsov, Sov. Phys.-Semicond. 10, 265 (1976).

${ }^{5}$ G. Foti, E. Rimini, G. Vitali, and M. Bertolotti, Appl. Phys. (to be published) and private communications; see also, H.D. Geiler, G. Götz, K. -D. Klinge, and N. Triem, Phys. Status Solidi A 41, K171 (1977); J. Krynicki, J. Suski, S. Ugniewski, R. Grötzschel, R. Klabes, U, Kreissig, and J. Rüdiger, Phys. Lett. A 61, 181 (1977).

${ }^{6}$ G. A. Kachurin, N.B. Pridachin, and L.S. Smirnov, Sov. Phys. -Semicond. 9, 946 (1976).

${ }^{7} \mathrm{~J}$. Mayer, L. Eriksson, and J. Davies, Ion Implantation in Semiconductors (Academic, New York, 1970).

${ }^{8}$ I.V. Mitchell, J.W. Mayer, J.K. Kung, and W. G. Spitzer, J. Appl, Phys. 42, 3982 (1971).

\title{
Fast diffusion of elevated-temperature ion-implanted $\mathrm{Se}$ in GaAs as measured by secondary ion mass spectrometrya)
}

\author{
A. Lidow and J. F. Gibbons \\ Stanford Electronics Laboratories, Stanford University, Stanford, California 94305 \\ V. R. Deline and C. A. Evans, Jr. \\ Materials Research Laboratory and School of Chemical Science, University of Illinois, Urbana, \\ Illinois 61801 \\ (Received 27 September 1977; accepted for publication 22 November 1977)
}

Depth profiles of Se-implanted GaAs samples have been measured as a function of substrate temperature during ion implanation using secondary ion mass spectrometry (SIMS). It has been found that Se diffuses anomalously fast during the implantation and that this diffusion is independent of implant time. Annealing of these implanted layers following the implantation, however, produces no additional diffusion even when annealed at $1000^{\circ} \mathrm{C}$ for $15 \mathrm{~min}$.

PACS numbers: $61.80 . \mathrm{Jh}, 66.30 . \mathrm{Jt}, 61.70 . \mathrm{Wp}, 82.80 . \mathrm{Ms}$

It has long been known that, in order to achieve high electrical activity after annealing of high-dose ion-implanted selenium and tellurium in GaAs, it is necessary to implant while maintaining the substrate at a temperature greater than $100^{\circ} \mathrm{C}$. Takai et al ${ }^{1}$ have shown that elevated implant temperatures cause implanted $\mathrm{Te}$ to rest on substitutional rather than interstitial sites. The effect of these elevated temperatures on resulting impurity profiles, however, has not been investigated due to the lack of a sensitive analysis technique which can measure as-implanted selenium or tellurium concentrations.

We have used secondary ion mass spectrometry (SIMS) to measure as-implanted profiles of selenium in $\mathrm{Cr}$-doped, lightly $p$-type, and heavily $n$-type substrates as a function of implant temperature and have found that the Se diffusion during ion implantation is greatly enhanced for substrate temperatures higher than $100^{\circ} \mathrm{C}$. No effect of substrate doping was observed in these experiments.

The $\mathrm{Cr}$-doped [100] substrates used for much of this study came from Sumitomo, whereas the [100] $n$-type $\left(1.6 \times 10^{18} \mathrm{Te} / \mathrm{cm}^{2}\right)$ and $[100] p$-type $\left(2 \times 10^{16} \mathrm{Zn} / \mathrm{cm}^{3}\right)$ substrates were from Crystal Specialties. Prior to implantation, all samples were cleaned in boiling TCE, boiling acetone, boiling isopropyl alcohol, followed by

\footnotetext{
a) Work supported by the Army Research Office, Durham, Contract DAHC-75-G0156 and National Science Foundation Grants DMR-76-01058 and CHE-76-03694.
}

a deionized water rinse, a $50: 1 \mathrm{H}_{2} \mathrm{O}: \mathrm{HF}$ dip, and another deionized water rinse.

Ion implantation was performed with the samples tilted $10^{\circ}$ with respect to the incident ion beam.All samples were placed in a heated section of beam line

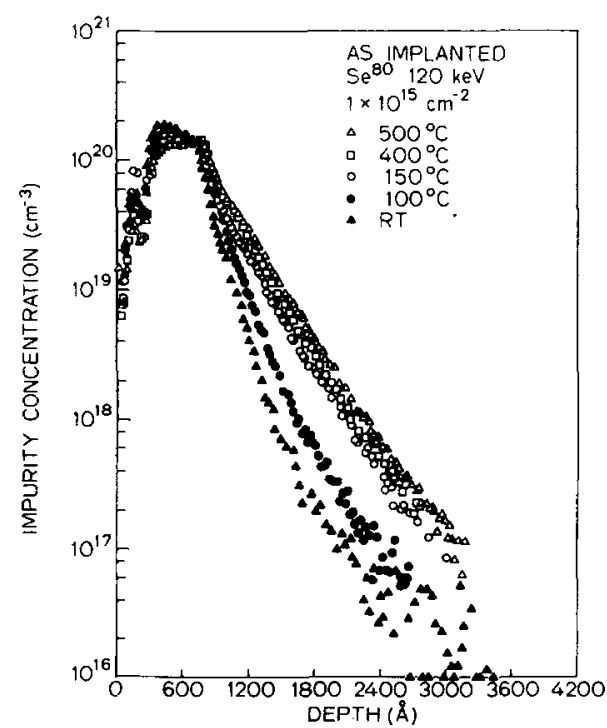

FIG. 1. SIMS profiles for as-implanted Se at $120 \mathrm{keV}$ to a dose of $1 \times 10^{15} \mathrm{~cm}^{-2}$. Substrate temperatures during implant were $22^{\circ} \mathrm{C}$ (closed triangles), $100^{\circ} \mathrm{C}$ (closed circles), $150^{\circ} \mathrm{C}$ (open circles), $400^{\circ} \mathrm{C}$ (open squares), and $500^{\circ} \mathrm{C}$ (open triangles). 